This is an Accepted Manuscript of an article published by Taylor \& Francis in Architectural Science Review on 02/04/2017, available online:

http://www.tandfonline.com/10.1080/00038628.2017.1300870.

E-prints may be viewed at:

http://www.tandfonline.com/eprint/abUI5JS65apniscUTEJe/full

or

http://www.tandfonline.com/eprint/8npiXaDIzunsgT43zcb5/full

\title{
The Influence of Roof Reflectivity on Adjacent Air and Surface Temperatures
}

\author{
Elizabeth J. Grant ${ }^{\mathrm{a}^{*}}$, K. A. Black ${ }^{\mathrm{b}}$ and S. R. Werre ${ }^{\mathrm{c}}$ \\ a School of Architecture + Design, Virginia Polytechnic Institute and State University, \\ Blacksburg, USA; ${ }^{b}$ School of Architecture + Design, Virginia Polytechnic Institute and \\ State University, Blacksburg, USA; ' Research \& Graduate Studies, Virginia-Maryland \\ College of Veterinary Medicine, Blacksburg, USA \\ Elizabeth Joyce Grant, School of Architecture + Design, 201 Cowgill Hall (0205), \\ Blacksburg, Virginia, 24061 USA, Phone +1 5402310609, elizabeth@vt.edu, ORCID:
} 0000-0002-5468-7990, https://www.linkedin.com/in/elizabethjoycegrant.

Kenneth Allan Black, School of Architecture + Design, 201 Cowgill Hall (0205), Blacksburg, Virginia, 24061 USA, Phone +1 7576460866, kenblack@vt.edu, ORCID: 0000-0001-8236-9781.

Stephen Rakem Werre, Virginia-Maryland College of Veterinary Medicine, Research \& Graduate Studies, 205 Duck Pond Drive, Room 249, Blacksburg, Virginia, 24061 USA, Phone +1 5402313522, swerre@vt.edu.

Word count: 4,623 


\title{
The Influence of Roof Reflectivity on Adjacent Air and Surface Temperatures
}

\author{
An experimental study was conducted to answer questions about the thermal \\ effects of roof reflectivity on the neighbouring built environment. Temperatures \\ were recorded at the surface of black ethylene propylene diene monomer (EPDM) \\ and white thermoplastic polyolefin (TPO) membrane overlay areas; in the air and \\ at electrical metallic tubing (EMT) above them; and at opaque and glazed wall \\ surfaces adjacent to them. The surface of the EPDM roof was significantly hotter \\ than the TPO roof by $36^{\circ} \mathrm{C}$ and $26^{\circ} \mathrm{C}$ on two test dates. Air temperatures were $2^{\circ} \mathrm{C}$ \\ higher above EPDM versus TPO up to $14 \mathrm{~cm}$, with no significant differences \\ above this height. Temperatures were $2^{\circ} \mathrm{C}$ higher at EMT above the TPO surface \\ than above the EPDM. A precast concrete panel wall was $3^{\circ} \mathrm{C}$ to $5^{\circ} \mathrm{C}$ warmer \\ adjacent to TPO versus EPDM. Exterior glazing surface temperatures were $2^{\circ} \mathrm{C}$ \\ warmer adjacent to TPO versus EPDM.
}

Keywords: roof reflectance; cool roofs; single-ply roof membrane; building envelope; roof design; solar radiation

\section{Introduction}

The role of reflective roofs in reducing global warming, the heat island effect, and unwanted thermal gains in buildings has been a subject of extensive research and debate in North America over the past few decades. Roofing consultants, architects, contractors, building owners and others keen to make informed decisions about roofing products are turning to the scientific community for guidance. Akbari and Konopacki (2005) estimated the cooling-energy use savings impact of implementing cool roofs, generally defined as roofs with both high solar reflectance and high thermal emittance, along with other heatisland reducing building material and pavement strategies for a range of building types 
and locations. They explained that hot surfaces warm the air around them, and that cool roofs are one strategy to minimize this indirect effect. In a later paper, Levinson and Akbari (2010) made a case for cool roofing. They claimed that cool roofs reduce temperatures at roof surfaces, thus reducing heat flow into buildings while also contributing to a decrease in production of greenhouse gases thanks to reduced cooling energy consumption. In one manifestation of the trend toward adoption of cool roofs, ASHRAE Standard 90.1 (ANSI/ASHRAE/IES 2013) requires them on commercial projects, though only in the warm-weather portions of the United States falling within Climate Zones 1 through 3.

The roofing community has recently been circulating reports with differing implications for roof system selection. A widely-shared study by Jacobson and Ten Hoeve (2012) proposed that a wholesale replacement of existing roofing with cool roofs would likely reduce local temperatures near the earth’s surface, but due to a range of resultant radiant and thermal effects, could actually contribute to the overall warming of the planet.

It is clear that multiple factors are involved in roof system selection for a given project. These include climate and microclimate; product availability, familiarity and price; electrical and other utility costs in the region; the formal and material characteristics of the building itself; and the nature and preferences of its owners and users. While the debate continues at the larger scale, it is also informative to derive results from experiments that look at the smaller scale. As the focus of this research is on the effect of roof surface treatment on the air above the roof, and on temperatures of 
adjacent building components, findings from three key papers dealing with these more localized effects will be summarized below.

Ibrahim (2013) took measurements at black EPDM and white TPO roofs in Carlisle, Pennsylvania in July and August of 2011. Measurements were recorded five days a week at 9 AM, 12 PM, 3 PM, and 5 PM, at the roof surface and at unshielded sensors at $25,41,56$, and $86 \mathrm{~cm}$ above the roof in both cloudy and sunny conditions. He reported that the surface of the black EPDM roof ranged from $6^{\circ} \mathrm{C}$ to $26.3^{\circ} \mathrm{C}$ above the ambient air temperature, while the white TPO surface ranged from $9^{\circ} \mathrm{C}$ to $13^{\circ} \mathrm{C}$ above the ambient air temperature. Air temperatures were generally reported to be higher above white TPO than above black EPDM, though results varied across weather conditions, heights, and times of day.

Dupuis (2013) performed a study of air temperatures above ballasted EPDM, fully adhered black EPDM, fully adhered white TPO, fully adhered white PVC, fully adhered Hypalon, and intensive green roof surfaces near Chicago, Illinois in the summer of 2013. He recorded air temperatures at shielded sensors for about 14 days at one-minute intervals at the roof surface, and in the air at 30, 45, 60, 91, 120, 180, and $240 \mathrm{~cm}$ above the surface. He reported results of data gathered during the day under zero wind conditions. He described air temperatures at $30 \mathrm{~cm}$ above a fully adhered white TPO roof as higher than air temperatures above a fully adhered black EPDM roof, and stated that this trend held steady for all the data points recorded at these two conditions throughout the two-week study period. He further stated that there was not much difference in air temperatures observed across the study heights ranging from 30 to $240 \mathrm{~cm}$ above the roof 
surface. Averaging the aggregate data for all six roofs studied, the average difference in temperature between any two points between 30 and $240 \mathrm{~cm}$ was $0.6^{\circ} \mathrm{C}$. He explained this outcome as most likely a result of Rayleigh-Benard convection, whereby air above a hot surface is heated and rises in a complex, three-dimensional manner rather than in a linear gradient. He called for future controlled studies to more fully determine the impact of membrane surface type on air temperatures above roofs.

Lindsey, Black and Sharpe (2006) experimentally determined the temperatures of EMT and rigid non-metallic conduit in sunlight in an effort to determine more accurate ampacity corrections for electrical conductors running through them. They collected data in Las Vegas, Nevada, at one-minute intervals, and reported 15-minute averaged data. Heights of conduits measured were at the roof surface and at 1.6, 3.8, 8.8, 15, 30, and 91 $\mathrm{cm}$ above the roof. White mineral roll roofing, black mineral roll roofing, and white elastomeric-coated mineral roll roofing comprised the three test conditions. In terms of roof colour, they found that conduits were hotter when touching or within $2.5 \mathrm{~cm}$ of a black roof surface, but at heights greater than $2.5 \mathrm{~cm}$ up to $91 \mathrm{~cm}$, conduits were hotter above a white roof surface. Looking at height, they found that as the distance above the roof increased, the difference between the ambient air temperature and the interior temperature of the conduit decreased.

The study discussed in this paper addresses thermal questions raised in previous research using a rigorous, statistically analysed experimental approach with three replications of each test condition. The study area was chosen specifically for its formal characteristics. It represents a frequently occurring condition of a roof adjacent to a wall, 
where the effects of reflective roofing are different than those occurring in the field of the roof.

\section{Research questions}

The present study seeks to answer the following questions:

(1) What is the effect of roof membrane reflectivity on roof membrane surface temperature?

(2) What is the effect of roof membrane reflectivity on air temperatures at various heights above the roof surface?

(3) What is the effect of roof membrane reflectivity on temperatures of EMT at various heights above the roof surface?

(4) What is the effect of roof membrane reflectivity on temperatures of opaque wall surfaces adjacent and perpendicular to them?

(5) What is the effect of roof membrane reflectivity on temperatures of glazed wall surfaces adjacent and perpendicular to the roof surface?

\section{Materials and methods}

An experimental site on the roof of the Virginia-Maryland College of Veterinary Medicine at Virginia Tech was selected because it had both opaque and glazed wall areas adjacent to a low-slope roof. Further, it featured a safe roof access and was located far from a roof edge. The opaque wall adjacent to the study area faces west-southwest, and the glazed wall faces south-southwest. The opaque wall is composed of a $12 \mathrm{~cm}$ thick 
precast concrete panel over $5 \mathrm{~cm}$ of rigid insulation over a $12 \mathrm{~cm}$ deep air space over a 30 cm thick concrete masonry unit backup wall. The glazed wall is aluminium with double glazing. The roof assembly underneath the overlay membranes was installed in 2008 and is comprised of fully adhered $2 \mathrm{~mm}$ EPDM over fully adhered $12 \mathrm{~mm}$ glass-faced gypsum board over fully adhered 2 cm-per-meter tapered polyisocyanurate board insulation over an existing concrete deck. The roof is located over the conditioned central stores area of the building.

Figure 1. Diagram of Experimental Setup

During the week of August 10, 2015, 1.5 mm reinforced white TPO and 1.5 mm nonreinforced black EPDM from the same manufacturer were positioned at the roof site. A 12-by-6-meter overlay of each membrane was installed adjacent to the opaque wall, and a 6-by-6-meter overlay of each was installed next to the glazed wall (Figure 1). The membranes were installed over the existing EPDM membrane, using pressure-sensitive seam tape. On October 21, 2015, an albedometer was used to measure the reflectivity of the TPO and EPDM membranes. Readings on the TPO membrane began at 13:22 and ended at 13:35 Eastern Daylight Time (EDT). The readings for the EPDM membrane began at 13:42 and ended at 13:55 EDT. Reflectivity measurements were taken at 10second intervals during the monitoring periods. The TPO had an average reflectivity of 65.7\%, and the EPDM had an average reflectivity of 6.5\%. With this information, and using the Lawrence Berkeley National Laboratory calculation for Solar Reflectance Index (SRI), the TPO had an SRI of 80, and the EPDM had an SRI of 0.2. 
At each location of interest, three temperature sensors were installed. This provided three replications to allow for averaging of data and determination of the statistical significance of any temperature differences recorded. The accuracy of the temperature sensors was $< \pm 0.2^{\circ} \mathrm{C}$ from $0^{\circ}$ to $50^{\circ} \mathrm{C}$, with a resolution of $<0.03^{\circ} \mathrm{C}$ from $0^{\circ}$ to $50^{\circ} \mathrm{C}$.

Roof membrane surface temperatures were taken by embedding a temperature sensor in thermal compound and covering it with a self-adhering flashing patch of the same material as the underlying roof membrane.

For sensors measuring air temperature, radiation shields with solid bases were employed in lieu of standard solar radiation shields because they were indicated by the manufacturer for use ‘in locations exposed to direct or reflected solar radiation’ (Onset Computer Corporation 2016). This ensured a more accurate air temperature reading because the sensors themselves were not influenced differentially by sun reflecting off the membranes beneath. The large size of the shields and their placement around the tripod mast dictated the heights of these sensors, which were placed at $8,14,23$, and 86 cm above the roof surface.

Temperatures at EMT were taken by affixing the temperature sensor directly to the EMT with thermal compound, and wrapping the sensor with adhesive-backed composite construction tape and a layer of duct tape to protect the thermal compound from washing away in the rain. These sensors were placed at the same four heights as the shielded air temperature sensors. 
Temperature sensors were embedded in a bead of thermal compound and affixed to the precast concrete panel walls with small strips of super strength moulding tape to prevent pull-off. At the exterior surface of the glazed walls, clear, two-part, instant-mix epoxy was used to provide a direct connection to the glass. Opaque wall and glazing sensors were placed at heights of 56, 86, 132, and $162 \mathrm{~cm}$ as dictated by the geometry of the sun shield bisecting the glazed wall. Table 1 lists the experimental equipment used, and Figures 1 and 2 show the experimental setup.

Table 1. Sensor and Data Logging Equipment List

Figure 2. Photograph of Experimental Setup

\section{Calculation}

Data loggers began recording data at one-minute intervals on October 12, 2016. An exhaust louver located adjacent to the TPO roof overlay at the opaque wall had the potential to impact the results, so the mechanical systems affecting the area were temporarily shut down in an effort to isolate their effect. Data were retrieved for analysis on May 24 and 25, 2016, two warm sunny days with light winds, no rainfall, and similar average temperatures. The mechanical systems were shut down on May $24^{\text {th }}$ between 12:15 EDT and 16:00 EDT, and were running as usual on May $25^{\text {th }}$. Data recorded on both days were averaged over a 30-minute time range, centred on the time when the solar azimuth was perpendicular to the opaque wall being measured. This 30-minute average was taken to account for shifting winds, occasional passing clouds, and other slight variations in weather, and to accommodate the up-to-two-minute lag time of the 
temperature sensors. The same process was repeated on August 11 and 12, 2016, with the mechanical systems shut down from 12:30 EDT to $16: 30$ EDT on August $12^{\text {th }}$.

The temperatures of the glazed surfaces were tested on a different day from the rest of the building elements because, for roughly half of the year, the glass is blocked from reflections off of the overlay roofs by exterior shading elements. Additionally, the solar elevation angle is low enough to bounce exclusively off the treatment area, and not the existing black EPDM flashing adjacent to the glazed wall, only between the autumnal and vernal equinoxes (Figure 3). Data from March 8, 2016 were therefore used to evaluate temperatures on the exterior of the glazing when the solar azimuth was perpendicular to the glass. Readings from sensors at a height of $132 \mathrm{~cm}$ were not reported, as they were obstructed from light reflected from the overlay surfaces on that day by a shading element. This area of the roof is unaffected by the exhaust louver at the opaque wall.

Figure 3. Geometry of Direct and Reflected Sunlight at Glazed Wall Sensors

\section{Statistical analysis}

Normal probability plots showed that temperatures (the primary outcome) followed an approximately normal distribution. An analysis of the coefficients of variation between replicates for the roof surface temperature on May 24, 2016 showed a mean of 2.0\%, a standard deviation (SD) of $0.04 \%$, and a range from $1.94 \%$ to $2.12 \%$ at the EPDM roof and a mean of $1.19 \%$, an SD of $0.05 \%$ and a range from $1.07 \%$ to $1.30 \%$ at the TPO roof. On August 12, 2016, analysis yielded a mean of $1.67 \%$, an SD of $0.43 \%$, and a range 
from $1.07 \%$ to $2.31 \%$ for the EPDM roof and a mean of $3.60 \%$, an SD of $0.20 \%$, and a range from $3.34 \%$ to $3.97 \%$ at the TPO roof. Subsequently data were summarized as means or least squares means. To test the effects of type of roof membrane at different heights in the air, at the EMT, on the opaque wall or on the glazed wall, data were analysed using mixed model analysis of variance. The initial model included day, type of roof, and height as fixed effects. After excluding day, type of roof and height were the only fixed effects in the final model for each set of analyses. Sensor within type of roof was specified as the random effect. Statistical significance was set to $\mathrm{P}<0.05$. All analyses were performed using SAS version 9.4 (Cary, NC, USA).

\section{Results and discussion}

Data collected on the two pairs of days with similar weather, namely May 24 and 25, and August 11 and 12, 2016, were run through statistical analysis separately. The results of these analyses were statistically compared to determine whether or not the date of the study influenced the air temperatures and temperatures of building elements at the EPDM and TPO overlay conditions. While results were generally similar on May $24^{\text {th }}$ and $25^{\text {th }}$, and again on August $11^{\text {th }}$ and $12^{\text {th }}$, the match was not close enough to confidently rule out the possible effects of the exhaust louver at some of the sensor locations. For that reason, May 24 and August 12, 2016, the two days when the mechanical systems were temporarily shut down, were selected as representative for this study. The weather characteristics for the three dates selected for data analysis are shown in Table 2.

Table 2. Weather characteristics on dates of data analysis 
iSolar Azimuth and elevation angles were calculated for the centre of each time range using NOAA Solar Calculator at http://www.esrl.noaa.gov/gmd/grad/solcalc/.

Proceeding in the order of the research questions, averaged measurements from the sensors located at the roof surface; from the shielded air temperature sensors at various heights above the roof; from sensors at EMT at these same heights above the roof; and from wall temperature sensors at several heights are shown. Outcomes from both the test period on May 24, 2016 and the test period on August 12, 2016 are reported. Following this, results from the temperature sensors affixed to the exterior of the glazing are presented from the test period on March 8, 2016. Throughout, comparisons with a P value of less than 0.05 are deemed statistically significant. Non-significant comparisons are showed in greyed-out rows in the data tables.

Temperature data were recorded on May 24, 2016, a warm, dry day with a relatively high solar elevation. These results are presented below.

The difference in roof surface temperatures, indicated by a height of $0 \mathrm{~cm}$, was estimated at $35.34^{\circ} \mathrm{C}$, with the EPDM much hotter than the TPO (Figure 4, Table 3). The average shielded air temperature above the EPDM overlay membrane was approximately $2{ }^{\circ} \mathrm{C}$ hotter than the air temperature above the TPO at $8 \mathrm{~cm}$ and $14 \mathrm{~cm}$ above the roof surface. The air temperature differences at the higher elevations of $23 \mathrm{~cm}$ and $86 \mathrm{~cm}$ were not found to be statistically significant.

Figure 4. Average Roof Surface and Air Temperatures on May 24, 2016

Table 3. Statistical Analysis of Average Roof Surface and Air Temperatures on May 24, 2016 
At the EMT, all averaged temperature differences between the EPDM and TPO overlays were statistically significant except at $14 \mathrm{~cm}$ above the roof surface, where temperatures were nearly equal (Figure 5, Table 4). At the remaining heights, the EMT above the TPO roof was $2^{\circ} \mathrm{C}$ hotter than it was above the EPDM roof.

Figure 5. Average EMT Temperatures on May 24, 2016

Table 4. Statistical Analysis of Average EMT Temperatures on May 24, 2016

At heights of 56, 132, and $162 \mathrm{~cm}$ significant differences ranging from $3^{\circ} \mathrm{C}$ to $5^{\circ} \mathrm{C}$ were found at the precast concrete wall panels, with the wall next to the TPO roof hotter than the wall next to the EPDM roof (Figure 6, Table 5). No significant difference was found at $86 \mathrm{~cm}$ above the roof.

Figure 6. Average Wall Surface Temperatures on May 24, 2016

Table 5. Statistical Analysis of Average Wall Surface Temperatures on May 24, 2016

Data were also recorded during a second study period in an effort to validate the findings under hotter, more humid conditions, with a slightly lower solar elevation. The following results are from August 12, 2016.

The difference in temperature between EPDM and TPO overlay areas was significant at the roof surface and at the shielded air temperature sensors at 8 and $14 \mathrm{~cm}$ above the roof (Figure 7, Table 6). The sensors at 23 and $86 \mathrm{~cm}$ did not record a significant difference in temperature between the two treatments. The EPDM roof surface was a mean of $26.20^{\circ} \mathrm{C}$ hotter than the TPO roof. Where the differences were significant, air temperatures were again $2^{\circ} \mathrm{C}$ hotter above the EPDM than above the TPO. 
Figure 7. Average Roof Surface and Air Temperatures on August 12, 2016

Table 6. Statistical Analysis of Average Roof Surface and Air Temperatures on August 12, 2016

The difference in EMT temperatures above EPDM and TPO overlays was significant at heights of 8 and $86 \mathrm{~cm}$, with the EMT above the TPO roof about $2^{\circ} \mathrm{C}$ hotter than the EMT above the EPDM roof (Figure 8, Table 7). The differences in EMT temperatures at 14 and $23 \mathrm{~cm}$ were not significant.

Figure 8. Average EMT Temperatures on August 12, 2016

Table 7. Statistical Analysis of Average EMT Temperatures on August 12, 2016

The only significant finding at the wall surfaces occurred at a height of $162 \mathrm{~cm}$ above the roof surface (Figure 9, Table 8). There, the wall next to the TPO roof was estimated to be about $3^{\circ} \mathrm{C}$ warmer than the wall next to the EPDM roof.

Figure 9. Average Wall Surface Temperatures on August 12, 2016

Table 8. Statistical Analysis of Average Wall Surface Temperatures on August 12, 2016

On March 8, 2016, the difference in temperature for glazed walls adjacent to the EPDM and TPO surfaces was significant for all three heights evaluated, with the glazing adjacent to the TPO roof approximately $2^{\circ} \mathrm{C}$ hotter than the glazing adjacent to the EPDM roof (Figure 10, Table 9).

Figure 10. Average Exterior Glazing Surface Temperatures on March 8, 2016 
Table 9. Statistical Analysis of Average Exterior Glazing Surface Temperatures on March 8, 2016

\section{Conclusions}

General conclusions are drawn relative to the five research questions for the weather conditions tested.

(1) The surface of EPDM roofs was significantly hotter than the surface of TPO roofs on both May 24 and August 12, 2016. The relative temperature difference was more pronounced on May $24^{\text {th }}$, when the temperature was $6^{\circ} \mathrm{C}$ cooler than on August 12th.

(2) On both May $24^{\text {th }}$ and August $12^{\text {th }}$, air temperatures were significantly hotter above the EPDM roof than the TPO roof, by roughly $2^{\circ} \mathrm{C}$ at $8 \mathrm{~cm}$ above the roof, and $2^{\circ} \mathrm{C}$ at $14 \mathrm{~cm}$ above the roof. This generally contradicts results found by Ibrahim (2013) and Dupuis (2013), most likely because of the use of solar radiation shields with solid bases in the present study. Ibrahim’s study used unshielded sensors, while Dupuis’ study used standard solar radiation shields with open bases. Above $14 \mathrm{~cm}$, temperature differences between EPDM and TPO treatments were not found to be significant in the present study.

While Dupuis found little difference in air temperature by height at the roofs in his study, here, the isolated effect of height on measurements at each roof area was mixed. On May $24^{\text {th }}$, the difference in temperature by height on the EPDM roof was significant everywhere but between sensors at 14 and $23 \mathrm{~cm}$; at the TPO roof, the only significant height difference occurred between sensors at 8 
and $86 \mathrm{~cm}$. On August $12^{\text {th }}$, the only significant distinction at the EPDM roof was between heights of 8 and $86 \mathrm{~cm}$, and at the TPO roof, no significant differences were noted.

(3) On both May $24^{\text {th }}$ and August $12^{\text {th }}$, statistically significant temperature differences were evidenced at some, but not all, of the EMT locations. Where significant, temperatures were $2^{\circ} \mathrm{C}$ higher at EMT placed above the TPO surface. This aligns with Lindsey et al.'s (2006) findings, and it is likely due to the greater amount of solar reflectivity leading to more radiation on the metallic tubing above the white TPO surface.

As in Lindsey et al.’s study, there is a general trend toward lower EMT temperatures higher above the roof, and the effect of the height of the sensors on the temperature outcomes is significant in most cases. Exceptions are as follows. At the EPDM roof there was no significant temperature difference between sensors at 8 and $14 \mathrm{~cm}$ on either date, nor between the sensors at 23 and $86 \mathrm{~cm}$ on August $12^{\text {th }}$. At the TPO roof, there was no significant temperature difference between the sensors at 14 and $23 \mathrm{~cm}$ on May $24^{\text {th }}$.

(4) On May 24th, three of the four heights (all but $86 \mathrm{~cm}$ ) on the precast concrete panel wall were $3^{\circ} \mathrm{C}$ to $5^{\circ} \mathrm{C}$ warmer adjacent to the TPO roof than adjacent to the EPDM roof. On August $24^{\text {th }}$, only one significant difference of nearly $3^{\circ} \mathrm{C}$ occurred at $162 \mathrm{~cm}$. It may be hypothesized that the TPO roof reflected more heat energy onto the wall than did the EPDM. Temperature differences by height were found not to be statistically significant on either date, for either treatment. 
(5) Exterior glazing surface temperatures measured on March 8, 2016 were found to be approximately $2^{\circ} \mathrm{C}$ hotter adjacent to the TPO overlay as compared to the EPDM overlay area at all heights. Statistically, the difference in temperature by height for each condition was significant for all pairs of sensor heights except at the TPO roof where there was no significant difference between the temperatures at 86 and $162 \mathrm{~cm}$. Qualitatively, it is clear that the effect of direct sunlight falling only on the sensors at $56 \mathrm{~cm}$ above both roof treatments created much higher temperatures there than elsewhere. Despite this, the relative difference in temperature from EPDM to TPO was similar whether sensors were shaded from direct sun or not, most likely due to the greater reflectivity of the TPO.

The outcome of this work is a statistically verified set of experimental results demonstrating the effect of roof reflectivity on the temperature of the air above the roof and the temperature of a range of building components above and adjacent to it. The conclusions point to the need to carefully consider the consequences of roof system choice on placement of mechanical and electrical equipment on or adjacent to roofs. They also indicate the need to consider the thermal effect of reflective roofs on buildings where a roof is adjacent to a south- or west-facing façade.

\section{Acknowledgments}

This work was supported by the RCI Foundation which reviewed the study design. The RCI Foundation had no role in the study's implementation, the collection, analysis, or interpretation of data, the writing of this paper, or the decision to submit this article for 
publication. The authors would like to gratefully acknowledge the cooperation of Mark Helms, Pete Jobst, Bruce Lytton, Jason Pearman, Anthony Watson, Ed Wilson, and their colleagues at Virginia Tech Facilities Operations and Construction. Additionally, thanks go to the students on the project: Alyssa Brink, Dana Brink, Jeffrey Herring, Meera Murali, Sean O’Mara, Yonghoon Sheen, and Hannah Utter, for their hard work, especially on the hot days.

\section{References}

Akbari, Hashem., and Steven J. Konopacki. 2005. "Calculating energy-saving potentials of heat-island reduction strategies." Energy Policy 33 (6):721-56. doi: http://dx.doi.org/10.1016/j.enpol.2003.10.001.

ANSI/ASHRAE/IES. 2013. "ANSI/ASHRAE/IES Standard 90.1 Energy Standard for Buildings Except Low-Rise Residential Buildings (I-P Edition)."

Dupuis, Matt. 2013. "Air temperature on reflective roofs." Midwest Roofer, 16-7. Ibrahim, Samir. 2013. Where Does the Heat Go? A Look into Energy Performance of Reflective Membranes. Paper presented at the 28th RCI International Convention and Trade Show, Orlando, FL.

Jacobson, Mark Z., and John E. Ten Hoeve. 2012. "Effects of Urban Surfaces and White Roofs on Global and Regional Climate." Journal of Climate 25 (3):1028-44.

Levinson, Ronnen, and Hashem Akbari. 2010. "Potential benefits of cool roofs on commercial buildings: conserving energy, saving money, and reducing emission of greenhouse gases and air pollutants." Energy Efficiency 3 (1):53-109. doi: 10.1007/s12053-008-9038-2.

Lindsey, Travis C, William T. Black, and Peter A. Sharpe. 2006. "Effect of Rooftop Exposure on Ambient Temperatures Inside Conduits." IAEI NEWS (January/February):32-41. 
Onset Computer Corporation. "Solar Radiation Shield (assembled) Mounting." Onset Computer Corporation, Accessed August 22, 2016.

http://www.onsetcomp.com/products/mounting/m-rsa. 